\title{
Sustainable development in the regions of the Russian Federation: socio-economic aspect
}

\author{
Yuri Zharnikov ${ }^{1}$, Alexei Belousov ${ }^{2, *}$, and Anastasia Terskikh $^{2}$ \\ ${ }^{1}$ Belarus State Economic University, 220070 Minsk, Republic of Belarus \\ ${ }^{2}$ Irkutsk National Research Technical University, 664074 Irkutsk, Russia
}

\begin{abstract}
The article discusses the implementation of the concept of sustainable development, carried out within the framework of the corresponding target model, based on the principle of balancing economic, social and environmental development. The role of the economic block is decisive in the implementation of the target model of sustainable development. At the same time, social and environmental components act to a certain extent in the role of constraints and setting goals for economic development. What are the key goals of the economic block within the framework of the concept of sustainable development of society: ensuring employment of the population with decent wages, solving the problems of creating a safe and favorable climate for the socio-cultural development of society; creation of acceptable conditions for the preservation of the natural environment, capable of meeting the corresponding needs of present and future generations.
\end{abstract}

\section{Introduction}

Economic growth that ensures the fulfillment of the specified goals of the economic block is a new quality of economic development within the framework of the concept of sustainable development of society. According to V.V. Mantatova and L.V. Mantatova, ensuring sustainable development is possible on the basis of a revolutionary change in the spiritual values of an individual.

A rational approach based on a body of relevant knowledge and practice must be used to translate the principles of sustainable development into reality. The latter comes as a result of education - the fundamental component of the concept of "culture of sustainable development". Currently, many researchers propose to conduct specialized training in educational programs in the field of culture and philosophy of sustainable development. After all, only educated and competent people participating in the implementation of the sustainable development model can and are able to understand each other and make informed decisions [1].

In our opinion, the creation of appropriate programs should be carried out on the basis of existing knowledge, first of all, the study of the historical and current practice of the relationship between economic development and culture of various countries and their

\footnotetext{
* Corresponding author: dr0n.19@yandex.ru
} 
unions, peoples, religions, public formations [2]. We are talking about the analysis of the relationship, mutual influence of economic development and mass cultures.

In addition to education, culture is a system of stable values, beliefs, traditions, norms of behavior, which, as a rule, have a national identity, regulate the behavior of individuals and groups and help organize collective social life. These are all types and results of the creative activity of man and society. Value is a generally recognized norm, formed in a particular culture, which sets patterns and standards of behavior and influences the choice between possible behavioral alternatives. Values imply free choice, creativity of the individual in the selection of certain patterns of behavior [3].

Speaking about the culture of sustainable development, let us highlight its main purpose - serving two purposes: preserving the environment, the nature of harmonizing relations between people. Achieving these goals in many ways means the implementation of the environmental and social components of the long-term sustainable development of society.

At the same time, some researchers, in particular German authors, rank the development of culture and the preservation of cultural values as the fourth component of the concept of sustainable development, along with economic, social and environmental development.

First, culture as a factor in ensuring the economic, social and environmentally friendly development of society.

Second, culture as a component of the concept of sustainable development of society.

Third, culture as an independent branch of the economy [4].

Thus, we can talk about the special place of culture in ensuring sustainable development.

Anticipating the results of our research, we note that during their implementation we were guided by the following thesis of professors V.V. Mantatova and L.V. Mantatova: "The demand for sustainable development at the present stage of global evolutionism appears as the need for humanity to transition from a material-consumer society to a spiritual and creative civilization." This kind of transition is directly related to economic development as a basic component of sustainable development. In its process, a culture of sustainable development is formed, based on the values and norms of human existence, which determine a fair, respectful attitude towards living and future generations of people, as well as towards the natural environment. The active connection between economic development and culture is also confirmed by the fact that in almost every country in the world today, cultural institutions are actively functioning, closely associated with the tourism industry, the most important areas of which are acquaintance with admirable creations. Creator and the fruits of human labor. In fact, a new culture and philosophy is emerging, called the culture and philosophy of sustainable development.

\section{Research methodology}

To determine the key indicators of sustainable development in the economic aspect, the article uses: methods of comparative analysis, an empirical study of development problems from the point of view of the economy [5].

The philosophy of sustainable development is aimed at establishing a perfect socioeconomic development, focused on a fair and respectful attitude towards the present and future generations of people, as well as towards the natural environment. Since there is no limit to perfection, there is no time limit for the establishment of perfect sustainable development, but there is a constant striving to achieve it [6].

Considering the relationship between the concepts of "culture" and "economic development", one must keep in mind one more important circumstance. The word "culture" translated from Latin cultura means cultivation, upbringing, education, development, that is, the concept of "culture" means a conscious human activity in creating and ensuring the necessary conditions for his life, starting with competent, fruitful cultivation of the land. 
Thus, in the very originally laid down sense, the culture and development of society, including its economic development, are strongly interconnected [7].

The solution of large long-term socio-economic and environmental problems is possible only on the basis of a sufficiently high social and cultural level of the population, which is a supporter of the idea of sustainable development. Only such a society is able to set and achieve the programmatic goals of sustainable development. Today, German society is to a certain extent such a society. Society here means a community of people united by a commonality of various characteristics, in particular, territorial, social, economic and cultural life. As a society, various public entities can be considered: the population of territorial entities, collectives of various kinds of organizations and companies, groups of people by interests [8].

The acceptance of the concept of sustainable development by the world community provides societies of various levels of public entities with a unique opportunity to coherently solve their tasks in implementing sustainable development strategies [9]. Solving the problems of implementing the concept of sustainable development through the joint participation and efforts of various countries makes it possible to radically revise the structure of the needs of their societies. Examples are useful.

First example: an opportunity is provided to change views on the solution of the tasks of ensuring the security of countries from external aggression. By optimizing resources for these purposes, including on the basis of agreements on collective and international security, prospects are opening up for the implementation of balanced social, economic and environmentally friendly development in a more humane manner.

And another example from the sphere of excessive domestic consumerism. In the metropolis of Hong Kong, $1000 \mathrm{~T}$-shirts are thrown away every minute. The absurdity and severity of the consequences of this kind of consumer behavior for a single system of components of sustainable development are understandable, therefore, solutions are proposed in establishing a reasonable need, including in the field of fashionable clothes. In particular, such a modern trend as Slowfashion (slow fashion) as opposed to Fastfashion (fast fashion) is of interest. Slowfashion provides for the formation of style in clothing by creating a basic wardrobe by the consumer - "five things - twenty looks". Slowfashion is a sensible need for clothing, to a certain extent corresponding to the concept of sustainable development. The Slowfashion trend has the prospects of spreading to other spheres of consumption, and in the broadest sense [10].

In December 2002, the UN General Assembly adopted Resolution 57/254, which proclaimed the Decade of Education for Sustainable Development, covering 2005-2014. At the forums held in 2005 in India and Lithuania under the auspices of the United Nations, the idea of advanced education for sustainable development was proclaimed. In Vilnius, the DOS Economic Commission for Europe Strategy for Education for Sustainable Development was adopted, which was the first official document of a regional scale (including more than $25 \%$ of the countries of the world community) in the field of creating a new education model capable of ensuring the survival of civilization.

An important document on the topic under consideration for interested persons in the Russian Federation was the expert-analytical report of A.D. Ursul et al. Education for Sustainable Development in Russia: Problems and Prospects. However, in our opinion, insufficient attention is paid to the development of specific solutions in the field of ESD at present in the Russian Federation (and in Germany as well), and first of all from the side of government structures. It seems that these structures need to put the higher education system as the curator of the ESD sphere in order to solve the following two groups of tasks.

- Preparation of programs for end-to-end education of the population in the basics of the concept of sustainable development and their implementation using the most accessible forms of education, primarily with the involvement of the media. 
- Development of training programs for specialists of management structures of public entities of different levels for the implementation of projects in the concept of sustainable development [11].

- The behavioral model of society for the formation of goals and target priorities for sustainable development is based primarily on the conscious, reasonable formation of the needs of the corresponding society for material and spiritual values.

\section{Research results}

The source, the basis for the creation of material needs is nature, but its resources are not unlimited, as well as all the possibilities for the disposal of used material values. These needs must meet the selected level of social development of society and the Strategy for sustainable development as a whole. At the same time, the balance between material and spiritual values should become increasingly reasonable, leaning towards spiritual values. But only a society with the appropriate culture and knowledge is able to optimize its needs, determining rational socio-economic development and, as a result, a balanced load on the environment. Thus, such a society plays the role of a regulator and executor of the process of balanced social, economic and environmentally friendly development in a single, integral system "nature - society economy" [12].

Considering projects, in particular engineering and technical developments, in the context of the concept of sustainable development, it is necessary to talk about the impact of these projects, if implemented, on the integrative economy of sustainable development of a particular company - a socially and environmentally balanced efficient economy of the company's development [13].

As already noted, the practical implementation of the concept of sustainable development requires the active participation of all strata of society: authorities at all levels of government, business structures, organizations and the population. Within the framework of one state, this work begins with the development and adoption of an appropriate strategy for the country's sustainable development. On January 11, 2017, the Federal Government of Germany adopted the Sustainable Development Strategy for the period up to 2030.

It should be noted that each country, adhering to the vectors of sustainable development established by the Agreement, approaches the preparation of the Development Strategy in its country purely individually. The main factors that determine the goals of sustainable development in a particular country are the level of socio-economic development* in comparison with other countries and the degree of resolution of environmental problems. Germany occupies the most advanced positions in the world in terms of socio-economic development and solving environmental problems [14].

Here is a comparison of socio-cultural indicators in the countries in Table 1. 
Table 1. Comparative socio-economic indicators

\begin{tabular}{|l|c|c|c|}
\hline Country & $\begin{array}{c}\text { Per capita income, } \\
\text { gross per year, USD, } \\
\mathbf{2 0 1 9}\end{array}$ & $\begin{array}{c}\text { GDP per capita, } \\
\text { USD per year, } \\
\mathbf{2 0 1 9}\end{array}$ & $\begin{array}{c}\text { Average salary per capita } \\
\text { at purchasing power } \\
\text { parity USD, 2019 }\end{array}$ \\
\hline Norway & 81980 & 74940 & 3654 \\
\hline USA & 56850 & 59501 & 3263 \\
\hline Germany & 36267 & 44550 & 2470 \\
\hline Slovakia & 17010 & 17664 & 1258 \\
\hline Turkey & 11230 & 10512 & 1067 \\
\hline Russia & 9720 & 10608 & 570 \\
\hline Kazakhstan & 8810 & 8841 & 339 \\
\hline China & 8250 & 8643 & 623 \\
\hline Belarus & 5600 & 5760 & 400 \\
\hline Ukraine & 2310 & 2583 & - \\
\hline
\end{tabular}

The most important condition for the implementation of the concept of sustainable development is the presence of a corresponding strong political will of the country's leadership. If we turn to the history of the development of some successful countries, then, for example, in South Korea and Singapore, economic growth was ensured by rather tough actions of political leaders. The German federal government, guided by the principles of global responsibility, equality of generations and social integration, largely builds its foreign and domestic policy in accordance with the concept of sustainable development, which is essentially a national idea of Germany for the long term. Since the implementation of the concept of sustainable development, subject to periodic revision of its goals, will be in demand for more than one historical period, this is the task of many generations of the population of the country, and of the planet as a whole. With this attitude, German society, led by the Federal Government, has embarked on the path of achieving the targets of the Sustainable Development Strategy for the period up to 2030.

The Decree of the President of the Russian Federation "On National Goals and Strategic Objectives of the Development of the Russian Federation for the Period up to 2024" dated May 7, 2018 and the Strategy for Sustainable Development for the Period up to 2030, adopted on January 11, 2017 by the Federal Government of Germany, are program documents for all walks of life in these countries.

Let us highlight six key conditions for ensuring sustainable development at the level of an individual country.

The first is the creation of a system of end-to-end special education in the field of culture and philosophy of sustainable development.

The second is the existence of the Strategy for Sustainable Development adopted by the government of the country for the nearest period, indicating development vectors and specific targets.

Third - ensuring sustainable development - the adoption of the concept of sustainable development as a national idea of the country and the presence of the appropriate will of the political leadership of the state in the implementation of the Sustainable Development Strategy.

Fourth, communicating the goals of the Sustainable Development Strategy to all participants in its implementation, including in the process of teaching them the basic principles of philosophy and culture of sustainable development. The above is carried out using the capabilities of educational institutions; mass media; by organizing forums, discussion platforms, days and events "Sustainable Development" ("Nachhaltigkeit"); methodological and guidance materials from higher federal, sectoral, regional, municipal management structures. 
Fifth, the creation of target models and mechanisms for the implementation of the concept of sustainable development at the level of determining social structures - participants in the implementation of the Strategy for sustainable development.

Sixth, the creation of an effective organizational structure to support the process of achieving the goals of the Sustainable Development Strategy [15].

\section{The discussion of the results}

As already mentioned, the concept is based on the most important principle of the practical implementation of the concept of sustainable development - the principle of balanced economic, social and environmentally friendly development. According to the German Development Strategy until 2030, the principle of balancing the three pillars of the concept of sustainable development presupposes that sustainable development is ahead of social and economic development. This is the first thing. And second: the implementation of balanced, motivational social development based on the achieved economic development. The Strategy sets out the goal of an environmentally and socially acceptable increase in the productivity of the economy, as well as stable and reasonable economic growth [16].

Strategies for sustainable development of the country and transformed at the sectoral and regional levels, and then at the level of individual companies. At the same time, we note one peculiarity inherent in companies from the MLS sphere: for such companies, sustainable development targets are set both at the industry level and at the level of regions (municipalities) where their production sites are located, and regions (municipalities), on the territory which is the installation and operation of houses (Fig. 1.). Setting targets, targeting parameters of sustainable development is the subject of the activity of certain specialists. But the subject of the activity of economists and management specialists is the creation of the necessary organizational and economic mechanisms for the implementation of the chosen model of sustainable development.

Global Sustainable

Development Goals

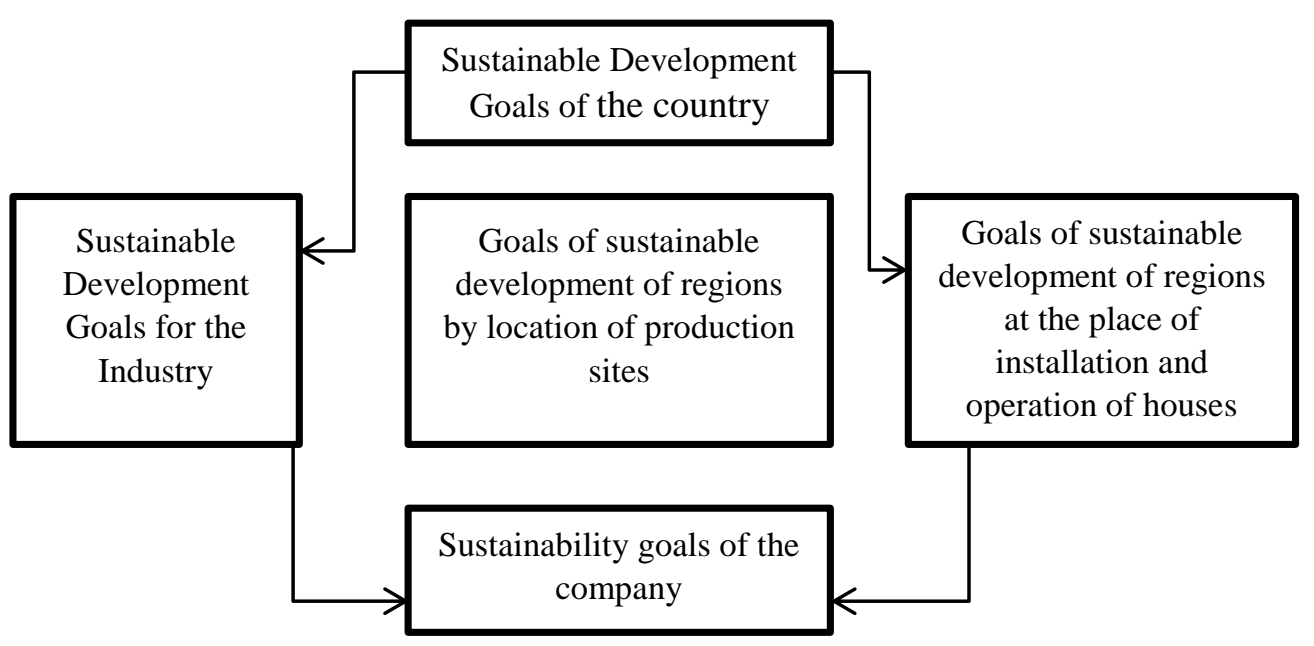

Fig. 1. Transformation of goals by levels of sustainable development 
Monitoring the implementation of the ratio of key, complex, integrated indicators answers the question of whether the company's activities comply with the basic principles of the concept of sustainable development [12]:

- balancing economic, social and environmentally friendly development;

- prioritizing social and environmentally friendly development over economic development.

But, given the circumstances of the company's life in a competitive, market environment, the implementation of only the above principles of the concept of sustainable development for the existence and development of the company is not enough. To develop in a competitive environment, a company must show the best results of its activities in terms of economic, social and environmental sustainability separately, both in relation to itself, but what is especially important, and in comparison with other homogeneous companies in the region in the context of its industry (grouped by industry principle) [17].

\section{Conclusions}

Thus, a system means a set of elements interconnected with each other, interacting in one way or another with each other, having something in common and pursuing a common goal. The definition of the system occurs through the identification of the basic properties inherent in the system. To define an economic system, it is important to identify, first of all, the economic laws and categories operating within its framework. Economic systems of different levels of the economy are considered as relatively stable, integral, structured and isolated objects of the economy, the elements of which, participating in the reproduction of material goods and production relations, occupy corresponding places in the structure hierarchy system and interact, realizing a large number of complex connections.

\section{References}

1. A. Nechaev, T. Romanova, M. Tyapkina MATEC Web of Conferences, 212, 09010 (2018)

2. Y. Barykina, IOP Conference Series, 667(1), 012011 (2019)

3. C. Azar, J. Holmberg, K. Lindgren, Ecological Economics, 18, 89 (1995).

4. G. Khokhlova, N. Kretova, V. Sergeev MATEC Web of Conferences, 212, 08019 (2018).

5. A. Nechaev, A. Prokopyeva, Economic Annals-XXI, 5-6, 72- (2014).

6. G. Broman, J. Holmberg, K-H. Robèrt, , International Journal of the Institute for Operations Research and the Management Sciences, 30, 3, (2000).

7. K.-H. Robèrt, B. Schmidt-Bleek, J. Aloisi de Larderel, G. Basile, L. Jansen, R. Kuehr, P. Price Thomas, M. Suzuki. UNEP Industry and Environment Review, 24 1-2 (2000).

8. G.I. Broman, S.H. Byggeth and K-H. Robèrt, International Journal of Engineering Education, 18, 6 (2002).

9. J. Korhonen. Journal of Cleaner Production, 12, 809 (2004).

10. A. Nechaev, A. Rasputina, IOP Conference Series, 421(3), 032010 (2020).

11. A.S. Nechaev, O.V. Antipina, Journal of Advanced Research in Law and Economics, 7 (3), 561 (2016).

12. S.V. Zakharov, Actual Problems of Economics, 166(4), 198 (2015).

13. J.L. Craig, Journal of the Royal Society of New Zealand, 34(1), 9 (2004). 
14. S.V. Zakharov, A.S. Bovkun, K.O. Vasiliev. International Conference " IT and QM and IS, 32, 8085754 (2017).

15. S.V. Zakharov, A.O. Troshina, A.U. Lobova, International Conference IT and QM and IS, 601, 8085895 (2017).

16. S. Zakharov, A. Shaukalova, IOP Conference Series, 667(1), 012108 (2019).

17. A.S. Nechaev, S.V. Zakharov, Y.N. Barykina, M.V. Vel'm, O.N. Kuznetsova, Journal of Sustainable Finance and Investment, 1 (2020). 